\title{
Approach via a small retroperitoneal anterior subcostal incision in the supine position for gasless laparoendoscopic single-port radical nephrectomy: initial experience of 42 patients
}

\author{
Tatsuo Morita*, Akira Fujisaki, Taro Kubo and Shinsuke Kurokawa
}

\begin{abstract}
Background: Gasless laparoendoscopic single-port surgery (GasLESS) for radical nephrectomy (GasLESSRN) in the flank position is a minimally invasive treatment option for patients with T1-3 renal cell carcinoma (RCC). However, RCC patients considered suitable for supine positioning rather than flank positioning for radical nephrectomy are occasionally encountered. This study evaluated the safety and feasibility of approach via a small retroperitoneal anterior subcostal incision (RASI) in the supine position for GasLESSRN (RASI-GasLESSRN) on the basis of our initial experience.
\end{abstract}

Methods: RASI-GasLESSRN was performed on 42 patients with RCC or suspected RCC from 2011-2013. The RASI, which was $6 \mathrm{~cm}$ long in principle, was made parallel to the tip of the rib from the lateral border of rectus abdominis muscle toward the flank in the supine position. The specimen was extracted via the RASI using a retrieval device. All procedures were performed retroperitoneally under flexible endoscopy with reusable instruments and without carbon dioxide insufflation or insertion of hands into the operative field.

Results: RASI-GasLESSRN was successfully performed in all patients without complications. The mean incision length was $6.3 \mathrm{~cm}$, mean operative time was 198 minutes, and mean blood loss was $284 \mathrm{~mL}$. All 42 patients were classified as Clavien grade I. The mean times to oral feeding and walking were 1.1 and 2 days, respectively. The mean number of postoperative days required for patients to be dischargeable was 3.7 days.

Conclusions: The approach via a small RASI in the supine position for GasLESSRN is a safe and feasible technique. RASI-GasLESSRN in the supine position is an alternative minimally invasive treatment option, especially for RCC patients considered suitable for supine positioning.

Keywords: Retroperitoneal anterior subcostal incision, Supine position, Renal cell carcinoma, Radical nephrectomy, Laparoendoscopic single-port surgery, Gasless laparoendoscopic single-port surgery

\section{Background}

There are various approaches and options for radical nephrectomy $(\mathrm{RN})$ for renal cell carcinoma $(\mathrm{RCC})$ : an open or laparoscopic approach; transperitoneally or retroperitoneally; via a single port, multiple ports, or a small incision; and with the patient in the supine position or flank position. However, the current RCC guidelines recommend the laparoscopic approach as the standard treatment or

\footnotetext{
* Correspondence: moritatu@jichi.ac.jp

* Correspondence: moritatu@jichi.ac.jp 3290498, Japan
}

(c) 2014 Morita et al.; licensee BioMed Central Ltd. This is an Open Access article distributed under the terms of the Creative Commons Attribution License (http://creativecommons.org/licenses/by/2.0), which permits unrestricted use, distribution, and reproduction in any medium, provided the original work is properly credited. The Creative Commons Public Domain Dedication waiver (http://creativecommons.org/publicdomain/zero/1.0/) applies to the data made available in this article, unless otherwise stated. preferred option for T2 RCC patients [1,2]. Laparoendoscopic single-port surgery (LESS)-RN was recently developed. In LESS-RN, all instruments are inserted via a small incision with [3] or without carbon dioxide [4-6]. For LESS-RN without carbon dioxide, Kihara et al. [7] developed gasless laparoendoscopic single-port surgery $\mathrm{RN}$ (GasLESSRN), which was previously termed "portless endoscopic urologic surgery" (PLES) [5] or "minimum incision endoscopic surgery" (MIES) [6]. GasLESSRN is performed retroperitoneally in the flank position via a small incision 4-6 cm long under endoscopic magnification; it is 
performed in combination with stereovision and without carbon dioxide, trocar ports, or inserting the hands into the operative field. This procedure has been demonstrated to be a safe, feasible, cost-effective, and minimally invasive treatment option for T1-3 RCC with oncologic outcomes equivalent to those with conventional open radical nephrectomy [8]. However, GasLESSRN has several advantages: (1) the small incision as a single port, which permits the extraction of the kidney covered with Gerota's fascia, is aesthetically advantageous; (2) carbon dioxide, which is a greenhouse gas associated with climate change [9] and confers a risk of pneumoperitoneum [10-12], is not required [13]; (3) the surgery uses reusable instruments, reducing waste and costs $[14,15]$, which is particularly advantageous in developing countries. The cost-effectiveness, smaller environmental impact, and minimal invasiveness of GasLESSRN collectively warrant the pursuit of this technique. On the other hand, the positioning and type of incision are important initial steps for successful surgery without complications; they should be chosen according to the disease status, patient's condition, and surgeon's experience. We occasionally encounter RCC patients suitable for supine positioning rather than flank positioning for $\mathrm{RN}$; these patients have conditions such as renal venous and/or arterial anomalies, lung diseases, and skeletal diseases or deformities as shown in living donor kidney harvesting [16]. Therefore, we adopted an approach via a small retroperitoneal anterior subcostal incision (RASI) in the supine position for RN, especially for GasLESSRN. Here, we present our initial experience and the details of an approach via a small RASI in the supine position for GasLESSRN, which is termed "RASI-GasLESSRN" herein.

\section{Methods}

\section{Patients}

A review of the medical records of Jichi Medical University Hospital revealed that from May 2011 to February 2013, RASI-GasLESSRN was performed on 42 patients with RCC or suspected RCC (Table 1). The present study was approved by the Institutional Review Board of Jichi Medical University, and informed consent was obtained from all patients.

\section{Surgical technique of RASI-GasLESSRN}

A schematic illustration of this procedure is shown in Figure 1. Under general anesthesia, the patient was placed in the supine position with back extension. A 16-Fr Foley catheter was indwelled, and a sequential compression device was placed on the lower extremities. A 6-cm subcostal incision, which varied depending on the size of the specimen to be extracted, was made from the lateral border of rectus abdominis muscle toward the flank parallel to the tip of the rib without cutting the rectus abdominis muscle. Only
Table 1 Patient characteristics and perioperative parameters

\begin{tabular}{ll}
\hline Number of patients & 42 \\
Age (years) & $63(46-79)^{\mathrm{a}}$ \\
Male/female & $28 / 14$ \\
Laterality (right/left) 21/21 & \\
Pathological examination & \\
$\quad$ Renal cell carcinoma & \\
$\quad$ pT1N0M0 & 32 \\
$\quad$ pT1N0M1 & 1 \\
$\quad$ pT2NOMO & 1 \\
$\quad$ pT3NOMO & 2 \\
Angiomyolipoma & 3 \\
Renal hematoma & 1 \\
Hydronephrosis & 2 \\
Incision length (cm) & $6.3(6-8)$ \\
Operation time (min) & $198(113-342)$ \\
Blood loss (mL) & $284(30-670)$ \\
Days to oral feeding & $1.1(1-2)$ \\
Days to walking & $2.0(1-3)$ \\
Postoperative hospital stay (days) ${ }^{c}$ & $3.7(3-5)$ \\
\hline
\end{tabular}

avalues are expressed as mean (range).

b pTNM pathological TNM stage.

'Postoperative days required for patients to be dischargeable, i.e., able to walk a long distance with full oral intake and without a drainage tube or analgesics.

the external oblique muscle was incised in the incision line, and the internal oblique and transverse muscles were split to avoid injuring the subcostal nerve without rib Resection. A surgical retractor (Gray Surgical Retractor System, Gray Surgical, Australia) was set, and subsequent procedures were performed using long instruments under direct vision and video imaging with a flexible endoscope. The lateroconal fascia (LCF) was exposed by excising surrounding fatty tissue (i.e., flank pads), and the landmark of the quadratus lumborum muscle was identified. The LCF was then incised longitudinally on the lateral or posterior side of the kidney, exposing Gerota's fascia. The peritoneum was retracted medially with blunt dissection to expose the anterior surface of the kidney covered with Gerota's fascia. A wound retractor (Alexis Wound Protector/Retractor ${ }^{\mathrm{Tm}}$, Applied Medical Resources Corp., USA) was set to obtain an adequate operative field. After dissecting toward the renal hilum, the renal artery and vein were exposed, double-ligated, and transected. For the left kidney, the adrenal, lumbar, and gonadal veins were ligated and transected. The ureter was isolated, ligated, and transected at the level of the lower pole of the kidney. After anterior, posterior, and medial dissection along Gerota's fascia, the cranial border of Gerota's fascia was dissected. Ipsilateral adrenalectomy was performed en bloc 

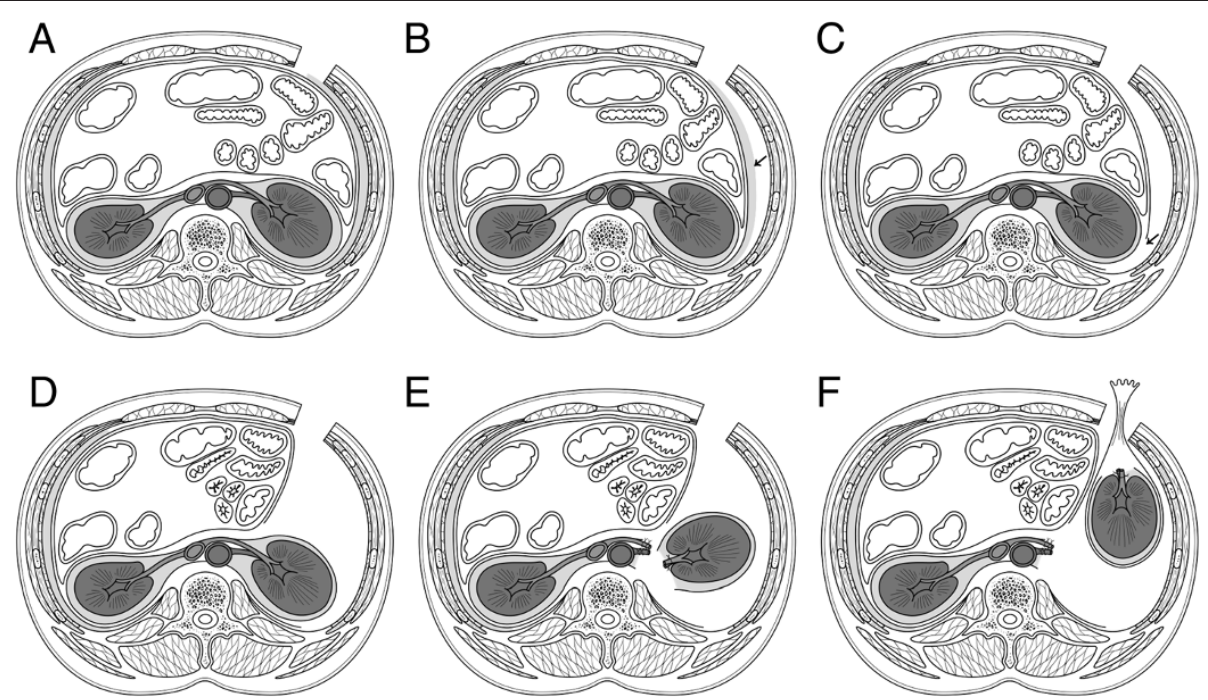

Figure 1 Schematic presentation of GasLESSRN via RASI in the supine position. (A) Subcostal skin incision. (B) Excision of fatty tissue $(\rightarrow)$ on the lateroconal fascia (LCF). (C) Incision of LCF $\rightarrow$ ) to expose Gerota's fascia. (D) Medial retraction of peritoneum. (E) Dissection of renal vessels and freeing the remaining renal attachments. (F) Extraction of the specimen via RASI using a retrieval device.

when necessary. After freeing the remaining renal attachments, the specimen was extracted via the RASI using a retrieval device (Kobamed Flexible Catcher ${ }^{\mathrm{rm}}$, Kobayashi Medical Co., Ltd., Japan) (Figure 2). Lymphadenectomy was performed when necessary. Hemostasis was carefully ensured. The dorsal spine extension was released after placing a 16-Fr drainage tube. All 3 muscle layers including the transverse abdominis, and internal and external oblique muscles were approximated using 1-0 monofilament polyglycolate sutures. The wound was subsequently washed with physiological saline. The skin was closed intracutaneously and covered with hydrocolloidal dressing (Karayahesive ${ }^{\mathrm{Tx}}$, ALCARE Co., Ltd., Japan). All procedures were performed without gas insufflation or inserting the hands into the operative field.
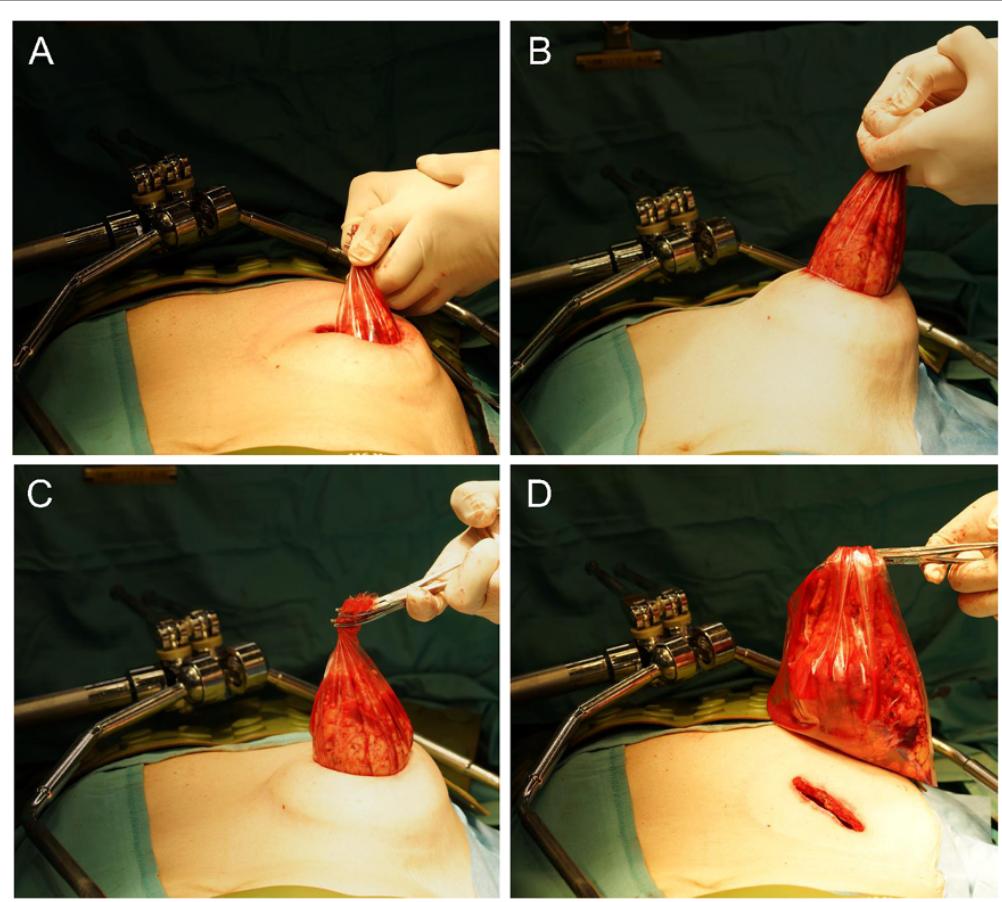

Figure 2 Specimen extraction. Images (A) before, $(\mathbf{B}, \mathbf{C})$ during, and (D) after specimen extraction via RASI using a retrieval device. 


\section{Results}

The perioperative data are summarized in Table 1 . RASI-GasLESSRN was successfully completed in all 42 patients without converting to conventional open RN. The mean operative time was 198 minutes, and mean estimated blood loss was $284 \mathrm{~mL}$. All specimens were retrieved successfully via the RASI, which had a mean length of $6.3 \mathrm{~cm}$. Pathological examination revealed RCC in 36 patients and benign renal diseases in 6 patients including 3,1 , and 2 with angiomyolipoma, renal hematoma, and hydronephrosis, respectively (Table 1 ). No blood transfusions were performed. All 42 patients were classified as Clavien grade I. The postoperative course was uneventful in all patients. The mean times to oral feeding and walking were 1.1 and 2 days, respectively. To evaluate hospital stay, we used the number of postoperative days required before patients were dischargeable, i.e., the ability to walk a long distance with full oral intake and without a drainage tube or analgesics [5]. In Japan, patients, particularly elderly patients, frequently choose to remain in the hospital for as long as possible after surgery, because the public medical insurance system covers most of the costs. Therefore, the mean number of postoperative days before patients were dischargeable was 3.7 days. All 36 RCC patients remained well without any evidence of recurrence at a mean follow-up of 22 months (range: 10-30 months).

\section{Discussion}

This study presents our initial experience with RASIGasLESSRN in the supine position. The principle surgical technique of GasLESSRN implemented in the present study is similar to that of Kihara et al. [4-6], except the approach via a small RASI in the supine position. Among the 80 cases of GasLESSRN in the flank position recently reported by Kihara et al. [5], the mean incision length was $6.6 \mathrm{~cm}$, mean operative time was $3.1 \mathrm{~h}$, and mean estimated blood loss was $324 \mathrm{~mL}$. In that series, complications included pleural injury and hemorrhage from the vena cava-both of which were repaired intraoperatively by suturing. Blood transfusion was performed in 3 patients (3.8\%). The mean numbers of days to oral feeding, long walking $(>100 \mathrm{~m})$, and possible minimal hospital stay were $1.4,1.4$, and 4.8 days, respectively. The present results (Table 1 ) are comparable to those of Kihara et al. [5], suggesting the approach via a small RASI in the supine position is a safe and feasible technique for GasLESSRN.

The approach via a small RASI in the supine position presented herein has several advantages. First, there is no delay due to the positional change from the supine to flank position. Second, supine positioning is helpful for RCC patients with skeletal diseases or deformities such as contralateral shoulder joint diseases, nonunion of the clavicle, and scoliosis [17]; it also avoids the potential risks associated with flank positioning, including peripheral nerve injuries such as brachial plexus neuropraxia [18], rhabdomyolysis $[19,20]$, unilateral pulmonary edema (i.e., down lung syndrome) [21], and atelectasis in the dependent lung [22,23]. Connor et al. [16] compared the anterior extraperitoneal approach to the flank approach for living donor open nephrectomy in a series of 36 familial donors; they conclude the former procedure confers not only superior visualization of the renal vessels, but also superior projected benefits for donors with obesity, age $>45$ years, pulmonary disease, multiple renal arteries, and skeletal deformities. Third, this anterior approach provides better visualization of the renal hilus, adrenal gland, and anterior surface of the kidney. In living donor kidney harvesting, a retroperitoneal anterior subcostal incision $[16,24,25]$ or pararectal incision [26] in the supine position provides excellent access to the renal vessels without serious complications. However, the most commonly used surgical approach for living donor kidney harvesting is performed in the flank position [27]. Furthermore, this advantage suggests RASI in the supine position can be applied to nephron-sparing surgery, which is currently the preferred option for T1 RCC [1,2], especially for RCCs located at the upper pole, anterior surface, or renal hilus. Finally, this anterior approach also provides a familiar anatomical view of the kidney, especially for surgeons familiar with conventional RN via a transperitoneal anterior subcostal incision (TASI) in the supine position [28]. Furthermore, it is easy to convert the approach into the conventional TASI with the incision of the peritoneum if required, although no such conversions were performed in the present series.

Despite its many advantages, the approach via RASI in the supine position has some limitations that should be mentioned. First, retracting the peritoneum medially and exposing the anterior side of the kidney covered with Gerota's fascia is occasionally time consuming; this is because the site of the lateral peritoneum reflection is located anterior to the posterior axillary line. Second, regarding aesthetics, the subcostal incision, which is not along Langer's lines, might result in the formation of an unsightly scar in the upper quadrant of the abdomen; meanwhile, a skin incision along Langer's lines heals with an almost invisible hairline scar [29]. Furthermore, the present study has some limitations including its retrospective nature, the small number of patients, a lack of comparison with other minimally invasive RNs, and the short follow-up period. Although the present study demonstrates the feasibility and safety of the technique of RASI-GasLESSRN in the supine position, further study is required to confirm the present results in RCC patients considered suitable for supine positioning rather than flank positioning. 


\section{Conclusions}

The results of the present study show for the first time that the approach via a small RASI in the supine position for GasLESSRN is a safe and feasible technique. Despite some drawbacks and limitations, RASI-GasLESSRN in the supine position is an alternative minimally invasive treatment option, especially for RCC patients considered suitable for supine positioning.

\section{Abbreviations}

RASI: Retroperitoneal anterior subcostal incision; RASI-GasLESSRN: Gasless laparoendoscopic single-port radical nephrectomy; RCC: Renal cell carcinoma; RN: Radical nephrectomy; LESS: Laparoendoscopic single-port surgery; LCF: Lateroconal fascia; MIES: Minimum incision endoscopic surgery; PLES: Portless endoscopic urologic surgery; TASI: Transperitoneal anterior subcostal incision.

\section{Competing interest}

The authors declare that they have no competing interests.

\section{Authors' contributions}

TM performed data collection and analysis, and drafted the manuscript. $\mathrm{TM}, \mathrm{AF}, \mathrm{TK}$, and SK performed the operations. All authors have read and approved the final manuscript.

\section{Acknowledgements}

This work has not been funded by any commercial company or grant.

Received: 12 November 2013 Accepted: 26 March 2014

Published: 4 April 2014

\section{References}

1. Ljungberg B, Cowan NC, Hanbury DC, Hora M, Kuczyk MA, Merseburger AS, Patard JJ, Mulders PF, Sinescu IC: EAU guidelines on renal cell carcinoma: the 2010 update. Eur Urol 2010, 58:398-406.

2. Escudier B, Eisen T, Porta C, Patard JJ, Khoo V, Algaba F, Mulders P, Kataja V: Renal cell carcinoma: ESMO Clinical Practice Guidelines for diagnosis, treatment and follow-up. Ann Oncol 2012, 23:vii65-vii71.

3. Greco F, Hoda MR, Mohammed N, Springer C, Fischer K, Fornara P. Laparoendoscopic single-site and conventional laparoscopic radical nephrectomy result in equivalent surgical trauma: preliminary results of a single-centre retrospective controlled study. Eur Urol 2012, 61(5):1048-1053.

4. Kihara K, Kawakami S, Fujii Y, Masuda H, Koga F, Saito K: Gasless single port access radical nephrectomy. Eur Urol 2009, 8(Suppl):392.

5. Kihara K, Kageyama Y, Yano M, Kobayashi T, Kawakami S, Fujii Y, Masuda H, Hyochi N: Portless endoscopic radical nephrectomy via a single minimum incision in 80 patients. Int J Urol 2004, 11:714-720.

6. Kihara K, Kawakami S, Fujii Y, Masuda H, Koga F: Gasless single-port access endoscopic surgery in urology: minimum incision endoscopic surgery, MIES. Int J Urol 2009, 16:791-800

7. Kihara K: Application of gasless laparoendoscopic single port surgery, GasLESS, to partial nephrectomy for renal cell carcinoma: GasLESSclampless partial nephrectomy as a multiply satisfactory method. Int $J$ Urol 2012, 19:3-4

8. limura Y, Kihara K, Saito K, Masuda H, Kobayashi T, Kawakami S: Oncological outcome of minimum incision endoscopic radical nephrectomy for pathologically organ confined renal cell carcinoma. Int J Urol 2008, 15:44-47.

9. Cox PM, Betts RA, Jones CD, Spall SA, Totterdell IJ: Acceleration of global warming due to carbon-cycle feedbacks in a coupled climate model. Nature 2000, 408:184-187.

10. Madeb R, Koniaris LG, Patel HR, Dana JF 2nd, Nativ O, Moskovitz B: Complications of laparoscopic urologic surgery. J Laparoendosc Adv Surg Tech A 2004, 14:287-301.

11. Giraudo G, Pantuso G, Festa F, Farinella E, Morino M: Clinical role of gasless laparoscopic adrenalectomy. Surg Laparosc Endosc Percutan Tech 2009, 19:329-332.
12. Elsamra S, Pareek G: Complications of laparoscopic renal surgery. Int J Urol 2010, 17:206-214.

13. Thompson T, Ballard T: Sustainable medicine: good for the environment goodfor people. Br J Gen Pract 2011, 61:3-4

14. Kwakye G, Brat GA, Makary MA: Green surgical practices for health care. Arch Surg 2011, 146:131-136.

15. Soga N, Kato M, Masui S, Nishikawa K, Hasegawa Y, Yamada Y, Kise H, Arima K, Sugimura Y: Comparison of radical nephrectomy techniques in one center: minimal incision portless endoscopic surgery versus laparoscopic surgery. Int J Urol 2008, 15:1018-1021.

16. Connor WT, Van Buren CT, Floyd M, Kahan BD: Anterior extraperitoneal donor nephrectomy. J Urol 1981, 126:443-447.

17. Stephen JS: Surgical Incisions. Operative Urology at the Cleveland Clinic, Totowa, NJ: Human Press Inc; 2006:1-16.

18. Shenoya S, Wardb P, Wigmorec T: Surgical management of urological malignancy: Anaesthetic and critical care considerations. Curr Anaesth Crit Care 2009, 20:22-27.

19. Reisiger KE, Landman J, Kibel A, Clayman RV: Laparoscopic renal surgery and the risk of rhabdomyolysis: diagnosis and treatment. Urology 2005, 66:29-35.

20. Deane LA, Lee HJ, Box GN, Abraham JB, Abdelshehid CS, Elchico ER, Alipanah R, Borin JF, Johnson RW, Jackson DJ, McDougall EM, Clayman RV: Third place: Flank position is associated with higher skin-to-surface interface pressures in men versus women: implications for laparoscopic renal surgery and the risk of rhabdomyolysis. J Endourol 2008, 22:1147-1151.

21. Snoy FJ, Woodside JR: Unilateral pulmonary edema (down lung syndrome)following urological operation. J Urol 1984, 132:776-777.

22. Klingstedt C, Hedenstierna G, Lundquist H, Strandberg A, Tokics L, Brismar B: The influence of body position and differential ventilation on lung dimensions and atelectasis formation in anaesthetized man. Acta Anaesthesiol Scand 1990, 34:315-322.

23. Pivalizza EG, Tonnesen AS: Acute life-threatening intraoperative atelectasis. Can J Anaesth 1994, 41:857-860

24. Baptista-Silva JC, de Figueiredo LF P, Câmara AL, Demuner MS, Castro MJ, Verissimo M, Medina-Pestana JO: Outcome of 605 consecutive living donor nephrectomies through an anterior subcostal retroperitoneal approach. Transplant Proc 2002, 34:451-452.

25. Srivastava A, Tripathi DM, Zaman W, Kumar A: Subcostal versus transcostal minidonor nephrectomy: is rib resection responsible for pain related donor morbidity. J Urol 2003, 170:738-740.

26. Schnitzbauer AA, Loss M, Hornung M, Glockzin G, Mantouvalou L, Krüger B, Krämer BK, Schlitt HJ, Obed A: Mini-incision for strictly retroperitoneal nephrectomy in living kidney donation vs flank incision. Nephrol Dial Transplant 2006, 21:2948-2952.

27. Dols LF, Kok NF, ljzermans JN: Live donor nephrectomy: a review of evidence for surgical techniques. Transpl Int 2010, 23:121-130.

28. Mejean A, Vogt B, Quazza JE, Chretien Y, Dufour B: Mortality and morbidity after nephrectomy for renal cell carcinoma using a transperitoneal anterior subcostal incision. Eur Urol 1999, 36:298-302.

29. Last RJ: Cosmetic principles in appendicectomy. Ann R Coll Surg Engl 1951, 8:155-159.

doi:10.1186/1471-2490-14-29

Cite this article as: Morita et al.: Approach via a small retroperitoneal anterior subcostal incision in the supine position for gasless laparoendoscopic single-port radical nephrectomy: initial experience of 42 patients. BMC Urology 2014 14:29. 